\title{
PERCEIVED STRESS MANAGEMENT AMONG THE MEDICAL STUDENTS IN ANNAMALAI UNIVERSITY, CHIDAMBARAM
}

\author{
Dr. R. Narayanan \\ Assistant Professor, \\ Department of Business Administration, Annamalai University. \\ https://doi.org/10.51705/AIJBSR.2019.v11i01.003
}

\begin{abstract}
Job stress has its roots in work. Environment and its effects on job attitudes and behaviour and mental health of the students are determined by various co-existing Organizational and personal characteristics. Technically, when a person perceives physical or psychological threat or challenge are termed as stress. But in general, when the mind feel uneasy, restless, disturbed, agitated, tense, heavy or strained them this state is called stress. Stress affects the normal routine and health of the students. It's difficult to find the perfect balance between too much challenge and too little coping is made all the more difficult because we are often unconscious of the stress we are suffering. Though there are various stress causing factors to an student, this extensive study aims at identifying the dominant stress factors and to arrive at the most suitable strategic approach to coping with stress, which would help to enhance the student effectiveness. The present study aims to Perceived Stress Management among the Medical Students in Annamalai University, Chidambaram. A samples of 150 medial students in Annamalai University selected randomly were studied. Primary data were collected by using a structured interview scheduled. All the respondents were asked the some questions in the same fashion and they were informed the purpose of study. ANOVA, Independent Sample t-test, Pearson Correlation and Regression analysis was applied to test the hypotheses. The findings and observations are the result and outcome of the interpretations made during the study of analysis.
\end{abstract}

Key-words: Stress Management, Treatment and Demographic Variables.

\section{Introduction}

The word stress is derived from Latin word "Stringers" which means "blind tight". Working people undergo much stress while they are on the work. Such occupational stress vary from person to person, occupation to occupation and time to time. "Occupational stress is defined as any adjective demand which occurs in the work place by physical, natural or emotional factors that require copying behaviour". Stress can be defined as a non-specific response of the body to any demand made upon it. Stress is a state produced by a change in the environment that is perceived as a challenging, threatening or damaging to the individual's dynamic equilibrium. Organisational stress is viewed as aundimensional psychological distress and it has been defined as "a condition arising from the interaction of people and their jobs and characterized by changes within people that face them to deviate from their normal functioning".

Stress has been defined in numerous and diverse ways to the point of confusion. Oxford dictionary defines the word stress as a "state of affair 